\title{
Autophagic Gene Polymorphisms in Liquid Biopsies and Outcome of Patients with Metastatic Clear Cell Renal Cell Carcinoma
}

\author{
MATTEO SANTONI ${ }^{1}$, FRANCESCO PIVA ${ }^{2}$, UGO DE GIORGI ${ }^{3}$, ALESSANDRA MOSCA ${ }^{4}$, UMBERTO BASSO ${ }^{5}$, \\ DANIELE SANTINI ${ }^{6}$, SEBASTIANO BUTI ${ }^{7}$, CRISTIAN LOLLI $^{3}$, CARLO TERRONE $^{8}$, MARCO MARUZZO $^{5}$, \\ MICHELE IULIANI $^{9}$, MELISSA BERSANELLI ${ }^{7}$, ALESSANDRO CONTI $^{10}$, ROBERTA MAZZUCCHELLI ${ }^{11}$, \\ RODOLFO MONTIRONI ${ }^{11}$, LUCIANO BURATTINI ${ }^{1}$ and ROSSANA BERARDI ${ }^{1}$ \\ ${ }^{1}$ Medical Oncology, Università Politecnica delle Marche, \\ Azienda Ospedaliero-Universitaria Ospedali Riuniti Umberto I, GM Lancisi, G Salesi, Ancona, Italy; \\ ${ }^{2}$ Department of Specialistic Clinical and Odontostomatological Sciences, \\ Polytechnic University of Marche, Ancona, Italy; \\ ${ }^{3}$ Istituto Scientifico Romagnolo per lo Studio e la Cura dei Tumori IRCCS, Meldola, Italy; \\ ${ }^{4}$ Medical Oncology, Maggiore della Carità University Hospital, University of Eastern Piedmont, Novara, Italy; \\ ${ }^{5}$ Medical Oncology Unit 1, Department of Clinical and Experimental Oncology, \\ Istituto Oncologico Veneto IOV IRCCS, Padua, Italy; \\ ${ }^{6}$ Medical Oncology, Campus Bio-Medico University of Rome, Rome, Italy; \\ ${ }^{7}$ Oncology Unit, University Hospital of Parma, Parma, Italy; \\ ${ }^{8}$ Division of Urology, San Martino Policlinic Hospital, University of Genoa, Genoa, Italy; \\ ${ }^{9}$ Laboratory of Translational Oncology, Medical Oncology, Campus Bio-Medico University of Rome, Rome, Italy; \\ ${ }^{10}$ Azienda Ospedaliera dell'Alto Adige, Bressanone/Brissen Hospital, Bressanone/Brissen, Italy; \\ ${ }^{11}$ Section of Pathological Anatomy, School of Medicine, United Hospitals, \\ Polytechnic University of the Marche Region, Ancona, Italy
}

\begin{abstract}
Background/Aim: Autophagy has been shown to be involved in cancer development and response to cancer therapy. In this study, genotypes of autophagic genes were analyzed to assess their correlation with the risk of clear cell renal cell carcinoma (ccRCC) and the outcome of patients treated with pazopanib for metastatic ccRCC. Materials and Methods: Single nucleotide polymorphisms (SNPs)were selected in the following genes: ATG4A (rs7880351), ATG4B (rs6709768), ATG4C (rs2886770, rs6670694, rs6683832), ATG5 (rs9373839, rs3804333, rs490010), ATG16L1 (rs6752107), ATG16L2 (rs10751215) and IRGM (rs10059011). The Kaplan-Meier method and log-rank test were used to evaluate differences between groups. Results:
\end{abstract}

Correspondence to: Matteo Santoni, MD, Department of Medical Oncology, AOU Ospedali Riuniti, Polytechnic University of the Marche Region, via Conca 71, 60126, Ancona, Italy. Tel: +39 0715964263, Fax: +390715964269, e-mail: mattymo@alice.it

Key Words: Autophagy, pazopanib, prognosis, progression-free survival, renal cell carcinoma, single nucleotide polymorphisms.
Forty patients with metastatic ccRCC treated with pazopanib were included in the analysis. ATG16L2rs10751215 was significantly less frequent in patients with ccRCC compared to the general population, suggesting its potential protective role, while ATG4Ars7880351, ATG4C rs6670694 and rs6683832 and ATG5 rs490010 were correlated with the progression-free survival (PFS) of patients treated with pazopanib. Conclusion: Our results suggest, for the first time, that autophagic gene SNPs are associated with ccRCC risk and patient outcome.

Renal cell carcinoma (RCC) is a malignancy arising from kidney parenchymal cells, with an incidence of approximately $3.7 \%$ and about 63,000 new cases expected in the United States in 2016 (1). Curative surgery, whenever possible, is the mainstay for localized or locally advanced forms. Nearly $20-25 \%$ of patients (depending on stage at diagnosis) will develop recurrent or metastatic disease after radical surgery, whilst $25-30 \%$ of patients present with metastatic disease $(2,3)$.

In the past years, we have witnessed a dramatic revolution in the therapeutic armamentarium of RCC, due to the 
introduction of novel target agents such as tyrosine kinase inhibitors (TKIs) sorafenib (4), sunitinib (5), pazopanib (6), axitinib (7) and cabozantinib (8) and mammalian target of rapamycin (mTOR) inhibitors temsirolimus (9) and everolimus (10). These drugs present considerable variations among their mechanisms of actions (11-16), that can explain the differences observed in terms of objective response rate (ORR), progression-free survival (PFS) and tolerability (4-10).

The autophagy consists in the degradation or the recycle of cytosolic components harmful to the cell or no more needed through the formation of a double membrane-layered autophagosome enwrapping cell constituents. When autophagosomes fuse with lysosomes (forming autophagolysosomes), the enzymatic activity leads to catabolism of sequestered components (17). In healthy cells, autophagy plays a homeostatic role for cell survival in stress conditions, nevertheless alterations in this process may cause cell death for "incomplete autophagy" or due to extreme vesicle storage (18). Autophagy related gene 4 (ATG4A), ATG4B and $A T G 4 C$ are 3 of the 4 ATG4 homologs (ATG4A-D) involved in autophagosome elongation (19). ATG5 is activated by ATG7 and forms complexes with ATG12-ATG16L1 and ATG12ATG16L2 that participates inautophagosome elongation through the formation of autophagy-related light chain 3 (LC3)-II protein (19). As for IRGM, it regulates the formation of autophagy initiation complexes (19). It has been reported that this process is involved in modulating the activity of TKIs and mTOR inhibitors in $\operatorname{RCC}(13,19,20)$.

It is interesting to note that sunitinib is a lysosomotropic agent; therefore, it is accumulated inside lysosomes inducing structural and functional alterations (13). In this manner, sunitinib is able to compromise autophagolysosomes generation and lysosomal enzymatic activity leading to "incomplete autophagy" in RCC cells (13). On the other hand, pazopanib can interfere with membrane trafficking (autophagosome formation and fusion with lysosomes) leading to accumulation of vesicles in the cell cytoplasm (13). As for everolimus, autophagy has been shown to be involved in the mechanisms of primary and acquired resistance to this drug in RCC models (13, 16-19).

In this study, we analyzed genotypes of some genes implicated in the autophagic process, aiming to verify whether they correlated with increased tumor risk and/or with the outcome of patients treated with first-line pazopanib for metastatic RCC.

\section{Materials and Methods}

Study population. The study population consisted of all consecutive patients aged 18 years or older treated with pazopanib for metastatic RCC in 6 Italian Institutions between 2011 and 2016. Other inclusion criteria included Eastern Cooperative Oncology Group (ECOG) performance status $\leq 2$; adequate organ function; no serious concomitant diseases. Patients were included consecutively to avoid
Table I. Patients' characteristics.

\begin{tabular}{lc}
\hline Chaeacteristics & $\begin{array}{c}\text { Patients, N }(\%) \\
(\mathrm{n}=40)\end{array}$ \\
& $65(43-81)$ \\
Median age, y (range) & $23(58)$ \\
Gender & $17(42)$ \\
Male & \\
Female & $40(100)$ \\
Tumor histology & \\
Clear cell & $3(7)$ \\
ISUP Grading & $12(30)$ \\
1 & $13(32)$ \\
2 & $5(13)$ \\
3 & $7(18)$ \\
4 & $11(28)$ \\
Unknown & $25(62)$ \\
Vascular infiltration & $4(10)$ \\
Yes & \\
No & $10(25)$ \\
Unknown & $30(75)$ \\
Disease status at RCC diagnosis & \\
Metastatic & $36(90)$ \\
Non-metastatic & $4(10)$ \\
Radical nephrectomy & $4(10)$ \\
Yes & \\
No & $15(38)$ \\
ECOG-PS $\geq 2$ & $22(56)$ \\
MSKCC risk group & $3(6)$ \\
Good & $26(65)$ \\
Intermediate & $18(45)$ \\
Poor & $4(10)$ \\
Lites of metastases & $7(18)$ \\
Lymph node & $1(3)$ \\
Liver & \\
Bone & \\
Brain & \\
\hline & \\
&
\end{tabular}

selection bias and were treated with pazopanib as first-line therapy according to the local guidelines of each participating Center. Pazopanib was continued until clinical and/or radiological progression or unacceptable adverse events or death. Follow-up was performed by physical examination, periodical laboratory analyses and computed tomography (CT) or magnetic resonance imaging (MRI) scans every 8-12 weeks.

Written informed consent was obtained from each subject and another consent for the biological procedures was obtained by alive patients. This study was carried out in accordance with the approval by the Ethical Committee of the institutions included in this study.

Single nucleotide polymorphism (SNP) selection, DNA extraction, genotyping and predictions. SNPs in the above-mentioned genes were selected using National Center for Biotechnology Information (NCBI) data and reviewing medical literature, according to the following criteria: 1) polymorphisms located in biologically relevant areas of the gene (i.e. intron, 5' UTR and 3' UTR or promoter region); 2) minor allele frequency (MAF) $\geq 10 \%$; 3) the genetic polymorphism was established and well documented. 
Table II. Position in the gene and base exchange of polymorphism studied group.

\begin{tabular}{|c|c|c|c|c|c|c|c|c|c|}
\hline Sample ID & $\begin{array}{l}\text { NCBI SNP } \\
\text { reference }\end{array}$ & Assay ID & $\begin{array}{c}\text { Reporter } 1 \\
\text { Dye }\end{array}$ & $\begin{array}{c}\text { Reporter } 1 \\
\text { Sequence }\end{array}$ & $\begin{array}{l}\text { Reporter } 1 \\
\text { Frequence }\end{array}$ & $\begin{array}{c}\text { Reporter } 2 \\
\text { Dye }\end{array}$ & $\begin{array}{c}\text { Reporter } 2 \\
\text { Sequence }\end{array}$ & $\begin{array}{l}\text { Reporter } 2 \\
\text { Frequence }\end{array}$ & Context sequence \\
\hline ATG4A & rs7880351 & C_266607_10 & VIC & G & 0.63 & FAM & $\mathrm{C}$ & 0.37 & $\begin{array}{c}\text { GCATAAGGGTTGCA } \\
\text { ATCAAGAAAGG(G/C) } \\
\text { AGCACCAGGCTTTG } \\
\text { GATGAAGAAAC }\end{array}$ \\
\hline ATG4B & rs6709768 & C_313966_10 & VIC & $\mathrm{C}$ & 0.44 & FAM & G & 0.56 & $\begin{array}{c}\text { ACTTTTGCACAGGTC } \\
\text { TGCTTGGTTA }(\mathrm{C} / \mathrm{G}) \\
\text { TGAAAGCATGTCTC } \\
\text { CCTTTCTAGGA }\end{array}$ \\
\hline \multirow[t]{3}{*}{ ATG4C } & rs 2886770 & C_15840433_10 & VIC & A & 0.38 & FAM & $\mathrm{G}$ & 0.62 & $\begin{array}{c}\text { CTGTTGAACTCTTTT } \\
\text { CTTCTCTGTG(A/G) } \\
\text { TTCCAAGTGTTTT } \\
\text { GATTATATACAT }\end{array}$ \\
\hline & rs6670694 & C_1767372_10 & VIC & A & 0.45 & FAM & G & 0.55 & $\begin{array}{c}\text { ATTGTGCATAAGGA } \\
\text { GACCTTATACT(A/G) } \\
\text { CAAAAAGATTTGC } \\
\text { AAAAAGTAGATG }\end{array}$ \\
\hline & rs6683832 & C_30152455_20 & VIC & A & 0.62 & FAM & G & 0.38 & $\begin{array}{c}\text { ATTTAATACAAGATT } \\
\text { CTTAAACTTG(A/G) } \\
\text { TTCTGTCTCTAT } \\
\text { TATTTAATTTCTA }\end{array}$ \\
\hline \multirow[t]{3}{*}{ ATG5 } & rs9373839 & C_3001898_10 & VIC & $\mathrm{C}$ & 0.21 & FAM & $\mathrm{T}$ & 0.79 & $\begin{array}{c}\text { ATCACAAACTTAAA } \\
\text { TCAGGTTTGAG(C/T) } \\
\text { CCTATGAGTTATA } \\
\text { TACAGTTACATG }\end{array}$ \\
\hline & rs 3804333 & C_1328945_10 & VIC & $\mathrm{C}$ & 0.79 & FAM & $\mathrm{T}$ & 0.21 & $\begin{array}{c}\text { TACCCAGAATTTTCC } \\
\text { ACTGTGACCA }(\mathrm{C} / \mathrm{T}) \\
\text { AGAAGGGTCATGA } \\
\text { CTAAGGAATAAA }\end{array}$ \\
\hline & rs490010 & C_1328956_10 & VIC & A & 0.47 & FAM & G & 0.53 & $\begin{array}{c}\text { GTCCCCTCTGTACT } \\
\text { TCCATATCCAC(A/G) } \\
\text { TCTACATGCAAG } \\
\text { ATTTTTGTTTTTT }\end{array}$ \\
\hline ATG16L1 & rs6752107 & C_9095450_10 & VIC & A & 0.58 & FAM & G & 0.42 & $\begin{array}{c}\text { TTCCCCTTACTGCTT } \\
\text { GCAGCTTAAG(A/G) } \\
\text { GTACAAAAATGTT } \\
\text { TGTACCTTTACC }\end{array}$ \\
\hline ATG16L2 & rs 10751215 & C_2064588_10 & VIC & $\mathrm{C}$ & 0.64 & FAM & $\mathrm{T}$ & 0.36 & $\begin{array}{c}\text { GGCTGTGCATCTCAG } \\
\text { GCTCTGCCGC(C/T) } \\
\text { GACAGGCGACGCT } \\
\text { GGCACAGGCTTA }\end{array}$ \\
\hline IRGM & rs 10059011 & C_30052989_10 & VIC & A & 0.49 & FAM & $\mathrm{C}$ & 0.51 & $\begin{array}{c}\text { CTCGGGGGTCAAAGG } \\
\text { CTGGTGGCTT(A/C) } \\
\text { CTTCACGTATATTG } \\
\text { CAGCATTTCAG }\end{array}$ \\
\hline
\end{tabular}

The genomic DNA of patients was extracted from blood, using the DNA Blood Mini kit according to the manufacturer's instructions. Genotyping of polymorphisms was performed using pre-designed TaqMan SNP Genotyping Assays (Applied Biosystems, Foster City, CA, USA), according to the manufacturer's instructions. Amplifications and analysis were carried out on the 7300 Real-Time PCR System (Applied Biosystems), using the SDS software v1.4.0 for allelic discrimination (Applied Biosystems). About $10 \%$ of samples were randomly remade for genotype confirmation and the results were $100 \%$ concordant. Data from general CEU population were provided by the HapMap project (www.HapMap.org). When these data were not available we considered the frequencies reported in the 1000 genome project (www.1000genomes.org).

The genotype frequencies of ATG4A, ATG4B, ATG4C, ATG5, ATG16L1, ATG16L2 and IRGM were checked for the Hardy-
Weinberg equilibrium (HWE) and linkage disequilibrium (LD), calculated using the Haploview 4.2 (Broad Institute, Cambridge, MA, USA). The most common genotypes in control subjects were considered as references.

To assess if a polymorphism can alter 5' and 3' splice sites, both genuine and cryptic, the NNSPLICE tool of the BDGP consortium was used (21). This tool uses an artificial neural network (ANN) algorithm trained with experimentally assessed data to estimate the splicing sites strength. Indeed, the higher the strength is, the higher the probability that the sequence is a splice site. To detect splice sites with higher sensitivity, Human Splicing Finder 3.0 was also used (22). Detailed indications for the interpretation of the consequences of the splicing site alteration events were previously reported (23).

SpliceAid2 tool has been used in order to predict if polymorphisms can alter binding sites for splicing regulatory factors 
(http://www.introni.it/spliceaid.html) (24). This resource detects only experimentally assessed target RNA sequences in order to reduce the false positive results. To interpret the predicted gain or loss of splicing factor, it should be taken into account that i) the gain of exonic silencers within an exon is usually a severe event that can lead to a partial or a total skipping of the concerned exon, ii) the loss of exonic silencers within an exon could alter the inclusion rate of an alternative exon, iii) the loss or gain of exonic enhancers is usually tolerated because these motifs are abundant in exons. The list of the splicing enhancer and silencer regulatory factors was previously published (25)

Statistical analysis. Data were collected from electronic and paper charts by the local physicians and checked at the central data management. Overall survival (OS) was calculated as the time from the date of first diagnosis to death or last follow-up visit. First-line OS was calculated from the start of treatment with pazopanib for metastatic disease to death or last follow-up. Patients who died without progression were censored at the time of death, whilst patients lost to follow-up were censored at the time of last contact

PFS was defined as the interval from the start of first-line therapy to disease progression or last follow-up or death. Disease-free survival (DFS) was defined as the time from surgery to disease recurrence. OS, PFS and DFS were evaluated with the Kaplan-Meier method and log-rank test were used to test differences between groups. A Cox-regression model was applied to the data with a univariate approach and used to assess the role of polymorphisms as prognostic factors. The association between categorical variables was assessed using the Fisher's exact test. All significance levels were set at a 0.05 value. Statistical analysis was performed with the MedCalc statistical software package version 11.4.4.0 (MedCalc Software, Broekstraat 52, 9030 Mariakerke, Belgium).

\section{Results}

Overall study population. Clinical data of 40 patients with metastatic RCC treated in 6 Italian centers were retrospectively collected. Twenty-three of them were males (58\%). Median age was 65 years (range $=43-81$ years). Tumor histology was clear cell in all patients. Thirty patients $(75 \%)$ had localized RCC at the time of first diagnosis and were treated with pazopanib at recurrence, while ten patients $(25 \%)$ were metastatic at presentation. The majority of included patients (90\%) were treated with radical nephrectomy at first diagnosis of RCC. A diagnosis of metastatic ccRCC, prognostic categories using Memorial Sloan Kettering Cancer Center (MSKCC)criteria were good in 15 patients $(38 \%)$, intermediate in 22 patients $(56 \%)$ and poor in 3 patients $(6 \%)$. The complete list of patient characteristics is shown in Table I.

Description of polymorphisms, Hardy-Weinberg equilibrium and linkage disequilibrium. Three SNPs were identified in $A T G 4 C$ (rs2886770, rs6670694, rs6683832) and ATG5 (rs9373839, rs3804333, rs490010). A single SNP was identified in $A T G 4 A$ (rs7880351), ATG4B (rs6709768), ATG16L1 (rs6752107), ATG16L2 (rs10751215) and IRGM (rs10059011). Position in the gene and base exchange are
Table III. Hardy-Weinberg equilibrium of selected SNPs. HWpval of a polymorphism is defined as the probability that its deviation from the $H$-W equilibrium could be explained by chance.

\begin{tabular}{lcclll}
\hline Gene & Id SNP & \multicolumn{1}{c}{ Position } & ObsHET & PredHET & HWpval \\
\hline ATG4C & rs6683832 & Chr 1: 62811233 & 0.5 & 0.483 & 1.0 \\
& rs2886770 & Chr 1: 62837115 & 0.475 & 0.485 & 1.0 \\
& rs6670694 & Chr 1: 62862187 & 0.41 & 0.492 & 0.426 \\
ATG5 & rs9373839 & Chr 6: 106207742 & 0.35 & 0.349 & 1.0 \\
& rs3804333 & Chr 6: 106279340 & 0.325 & 0.335 & 1.0 \\
& rs490010 & Chr 6: 106292583 & 0.395 & 0.5 & 0.2896 \\
ATG4B & rs6709768 & Chr2: 241666621 & 0.55 & 0.5 & 0.8125 \\
ATG16L1 & rs6752107 & Chr2: 233252802 & 0.4 & 0.495 & 0.3268 \\
IRGM & rs10059011 & Chr 5: 150847160 & 0.526 & 0.494 & 1.0 \\
ATG16L2 & rs10751215 & Chr 11: 72815042 & 0.575 & 0.497 & 0.5524 \\
ATG4A & rs7880351 & Chr X: 108111552 & 0.529 & 0.5 & 1.0 \\
\hline
\end{tabular}

shown in Table II. Based on values reported in Table III, no SNP was rejected. Figure 1 shows the pairwise linkage disequilibrium between any two polymorphisms of $A T G 4 C$ and ATG5 genes.

Genotyping and prognostic analyses. This study analyzed the SNP frequency of genes involved in autophagy in RCC compared with the general population. All frequencies and genotype distributions are shown in Table IV. The frequency of ATG16L2 polymorphism rs 10751215 was significantly lower in RCC than for general population (46\% vs. $64 \%$, $p=0.024$, Table IV). In addition, the frequency of ATG16LI polymorphism rs6752107 was lower in RCC than for general population ( $58 \% v s .45 \%$ ), although the difference was only slightly significant $(p=0.09)$. As for the other autophagic genes, we did not observe significant differences (Table IV).

No significant correlation was found between selected SNPs and gender, age, Fuhrman grade, tumor stage or sites of metastases. Median OS from diagnosis was 265.3 months (95\%CI=19.1-398.6). No significant differences were found based on gender or age $(\geq 65 \mathrm{y} v s .<65 \mathrm{y})$. As for the prognostic role of SNPs on OS, patients with the ATG4 Ars7880351 genotype had a significantly shorter OS (although not reached in both groups) compared to C and GC genotypes ( $p=0.03$, Figure 2 ).

Median OS from the start of pazopanib was 48.0 months (95\% CI=9.1-53.4). The OS was longer in females, although the difference was not significant (not reached $v s .48 .0$ months, $p=0.078$ ). No significant differences were found based on age or MSKCC groups or on selected SNPs.

Nineteen patients $(47.5 \%)$ experienced partial responses (PR), 1 (2.5\%) complete response (CR), 14 (35.0\%) had stable diseases (SD) and $6(15 \%)$ progressive diseases (PD). Median PFS was 13.1 months (95\%CI=3.9-37.6). No significant differences were found based on MSKCC group, gender or age 
ATG4C
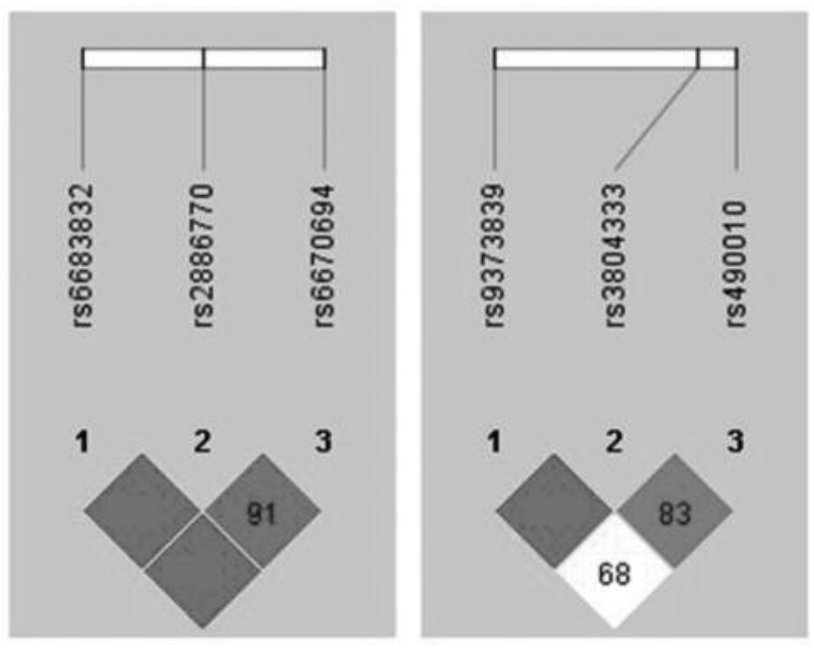

Figure 1. Linkage disequilibrium ( $D^{\prime}$ ') among genetic polymorphisms of ATG4C and ATG5 genes. ATG4C and ATG5 SNPs are in a $51 \mathrm{~Kb}$ and $85 \mathrm{~Kb}$ region respectively. Number inside the squares represents the $D^{\prime}$ value expressed as a percent. Squares without numbers represent D' values of 1.0, that is complete linkage disequilibrium. Darker shades represent stronger linkage disequilibrium.

( $\geq 65$ y $v s .<65$ y). Patients with ATG4 Ars7880351 Ggenotype ( $G$ for males, GG for females due to its location on $\mathrm{X}$ chromosome) had a significantly shorter PFS compared to females with CC and GC genotypes (16.7 vs. 23.9 months, $p=0.043$, Figure 3A). As for $A T G 4 C$ rs6670694, patients with AA and GA genotypes had longer PFS compared to GG (23.9 vs. 13.1 months, $p=0.067$, Figure 3B), while patients with $A T G 4 C$ rs6683832 AA had longer PFS than AG and GG (22.3 vs. 14.7 months, $p=0.110$, Figure $3 C$ ). In the studied population these two polymorphisms are in complete LD so they group into a haplotype block. It means also that, in our sample, we cannot establish if both or only one of them is causal (26).

Finally, patients with ATG5 rs 490010 GG genotype had shorter PFS compared to AA and AG (11.5 vs. not reached, $p=0.039$, Figure 3D).

No correlation was found between SNPs and the development of all-grade and high-grade adverse events. Of the 22 patients who progressed during first-line, 16 (73\%) received a second line therapy, with a median PFS of 5.5 months $(95 \% \mathrm{CI}=2.9-10.2)$. Of them $14(88 \%)$ were treated with everolimus and $2(12 \%)$ with sorafenib.

Results from computational analysis. Here we report the results of the predicted molecular effects due to the polymorphism based on the predictions of SpliceAid2 tool. When not specified, we assumed that the nucleotide variation

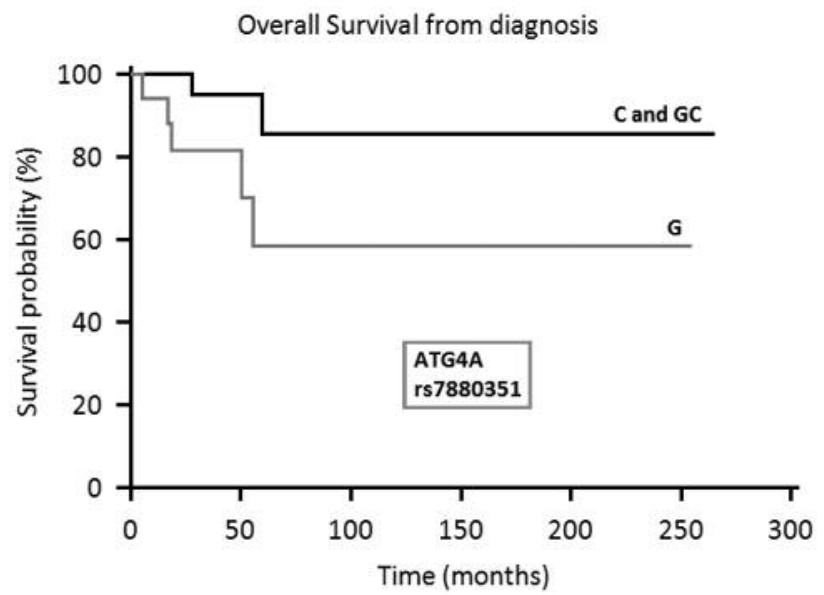

Figure 2. Overall survival according to ATG4A polymorphisms in patients treated with pazopanib for metastatic ccRCC.

lies within an intron, moreover only the predicted differences between alleles are reported in Figures 4 and 5.

rs7880351 polymorphism of the ATG4A autophagy related $4 \mathrm{~A}$, cysteine peptidase gene could create a binding site for SRp30c and SRp40 splicing proteins according to SpliceAid. HSF predicts that the $\mathrm{C}$ allele of rs7880351 causes the strengthening (score from 0.60 to 0.70 ) of a cryptic 3' splice site (caagaaaggcagCACCAGGCT). However, the score seems yet insufficient to activate the 3' splice site and provoke the inclusion of an ectopic exon during pre-mRNA splicing (Figure 4A).

rs6709768variation of the $A T G 4 B$ autophagy related 4B, cysteine peptidase gene lies within an intron, at 23bp upstream the 3'spicing site (ss). It reinforces four cryptic splice sites: a 5 'ss (CTGCTTGgttagtga with score 0.98) according to NNSPLICE, two 5'ss (CTTGGTTAgtgaaagc with score 0.67 and TCTGCTTGgttagtga with score 0.88 ) according to HSF, a 3'ss (gcttggttagTGAAAGC with score 0.73 ) according to HSF. Moreover, a binding site for the hnRNP A1 exonic silencer is created. Altogether, since the scores of two 5' splicing sites is higher than 0.80 it is possible that during splicing one of these 5 'ss is used and splicing alterations occur (Figure 4B).

rs 2886770 of the $A T G 4 C$ autophagy related $4 \mathrm{C}$, cysteine peptidase gene only weakly reinforces a cryptic 5'ss (TCTGTGgttccaa), according to HSF, so no effect is expected (Figure 4C).

rs6670694 of the ATG4C autophagy related 4C, cysteine peptidase gene could destroy the binding sites for hnRNP DL and SRp40 and create the binding site for SRp20. Since the loss of the SRp40 exonic enhancer is compensate by SRp20 and many other exonic silencers, apart from hnRNP DL, bind the intron, we deduce that this variation has not molecular effects (Figure 4D). 

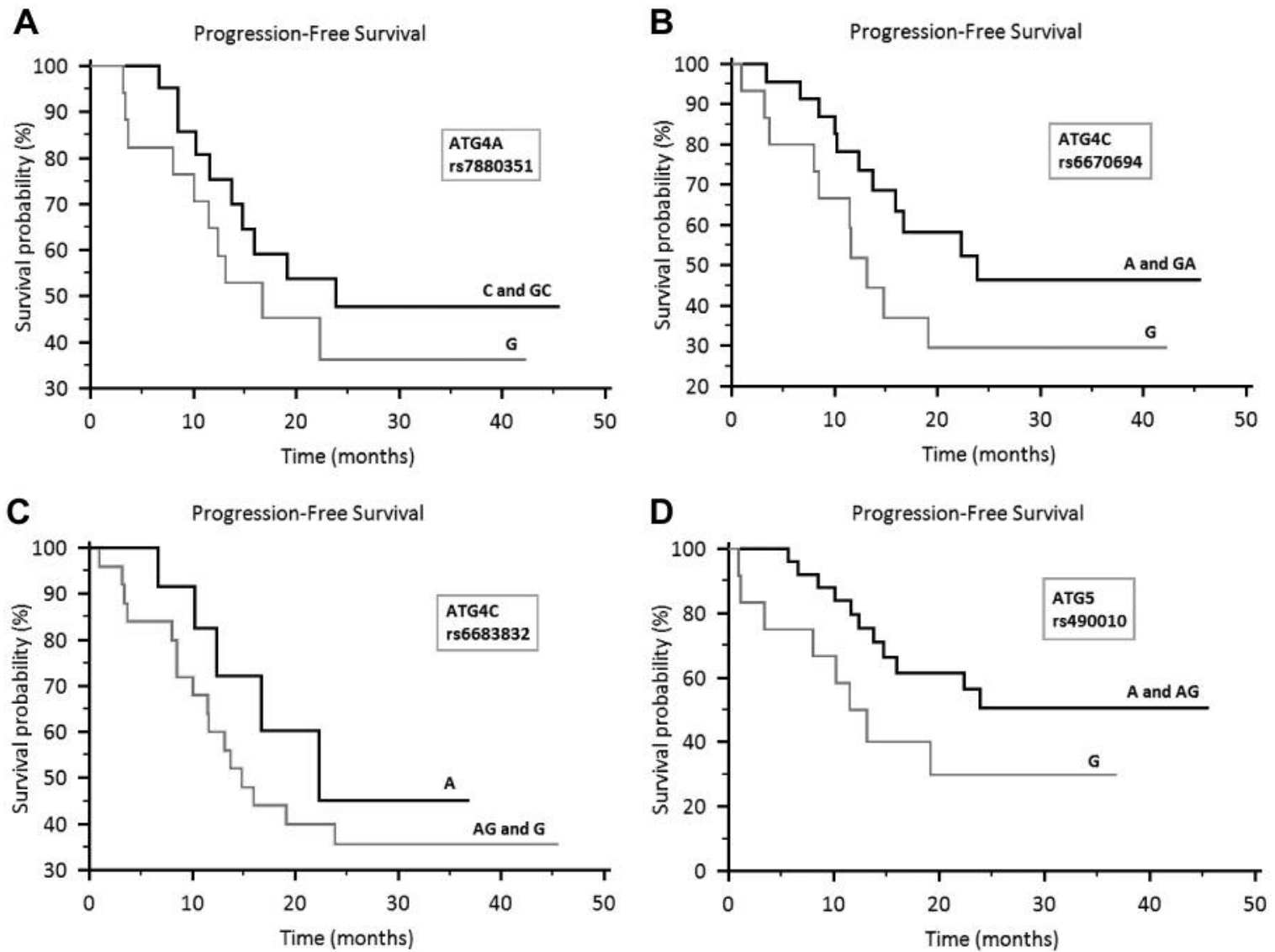

Figure 3. Progression-free survival according to ATG4A, ATG4C and ATG5 polymorphisms in patients treated with pazopanib for metastatic ccRCC.

Table IV. Genotype and allele frequencies of evaluated genes polymorphisms.

\begin{tabular}{|c|c|c|c|c|c|c|c|c|}
\hline Gene & SNPs & Allele & $\begin{array}{l}\text { Frequencies general } \\
\text { population }\end{array}$ & $\begin{array}{l}\text { Frequencies study } \\
\text { cohort }\end{array}$ & n. sample & $p$-Value & Yates & $\begin{array}{l}\text { Odds } \\
\text { Ratio }\end{array}$ \\
\hline \multirow[t]{2}{*}{$A T G 4 A$} & rs7880351 & G & $63 \%$ & $54 \%$ & $40 / 40$ & 0.2353 & 0.3047 & 1.47 \\
\hline & & $\mathrm{C}$ & $37 \%$ & $46 \%$ & & & & \\
\hline \multirow[t]{2}{*}{$A T G 4 B$} & rs6709768 & G & $56 \%$ & $50 \%$ & $40 / 40$ & 0.4471 & 0.5472 & 1.27 \\
\hline & & $\mathrm{C}$ & $44 \%$ & $50 \%$ & & & & \\
\hline \multirow[t]{2}{*}{$A T G 4 C$} & rs 2886770 & G & $62 \%$ & $59 \%$ & $40 / 40$ & 0.6743 & 0.7959 & 1.15 \\
\hline & & A & $38 \%$ & $41 \%$ & & & & \\
\hline \multirow[t]{2}{*}{$A T G 4 C$} & rs6670694 & G & $55 \%$ & $56 \%$ & $39 / 39$ & 0.8593 & 0.9871 & 0.94 \\
\hline & & A & $45 \%$ & $44 \%$ & & & & \\
\hline \multirow[t]{2}{*}{$A T G 4 C$} & rs6683832 & A & $62 \%$ & $59 \%$ & $38 / 38$ & 0.7249 & 0.8525 & 1.12 \\
\hline & & G & $38 \%$ & $41 \%$ & & & & \\
\hline \multirow[t]{2}{*}{ ATG5 } & rs9373839 & $\mathrm{T}$ & $79 \%$ & $78 \%$ & $40 / 40$ & 0.8181 & 0.9694 & 1.09 \\
\hline & & $\mathrm{C}$ & $21 \%$ & $23 \%$ & & & & \\
\hline \multirow[t]{2}{*}{ ATG5 } & rs3804333 & $\mathrm{C}$ & $79 \%$ & $79 \%$ & $40 / 40$ & 0.9691 & 0.8769 & 1.02 \\
\hline & & $\mathrm{T}$ & $21 \%$ & $21 \%$ & & & & \\
\hline \multirow[t]{2}{*}{ ATG5 } & rs490010 & G & $53 \%$ & $50 \%$ & $37 / 37$ & 0.7150 & 0.8410 & 1.13 \\
\hline & & A & $47 \%$ & $50 \%$ & & & & \\
\hline \multirow[t]{2}{*}{$A T G 16 L 1$} & rs6752107 & A & $58 \%$ & $45 \%$ & $40 / 40$ & 0.0999 & 0.1370 & 1.69 \\
\hline & & G & $42 \%$ & $55 \%$ & & & & \\
\hline \multirow[t]{2}{*}{$A T G 16 L 2$} & rs 10751215 & $\mathrm{C}$ & $64 \%$ & $46 \%$ & $40 / 40$ & 0.0240 & 0.0359 & 2.07 \\
\hline & & $\mathrm{T}$ & $36 \%$ & $54 \%$ & & & & \\
\hline \multirow[t]{2}{*}{$I R G M$} & rs 10059011 & $\mathrm{C}$ & $51 \%$ & $45 \%$ & $38 / 38$ & 0.4396 & 0.5415 & 1.29 \\
\hline & & A & $49 \%$ & $55 \%$ & & & & \\
\hline
\end{tabular}




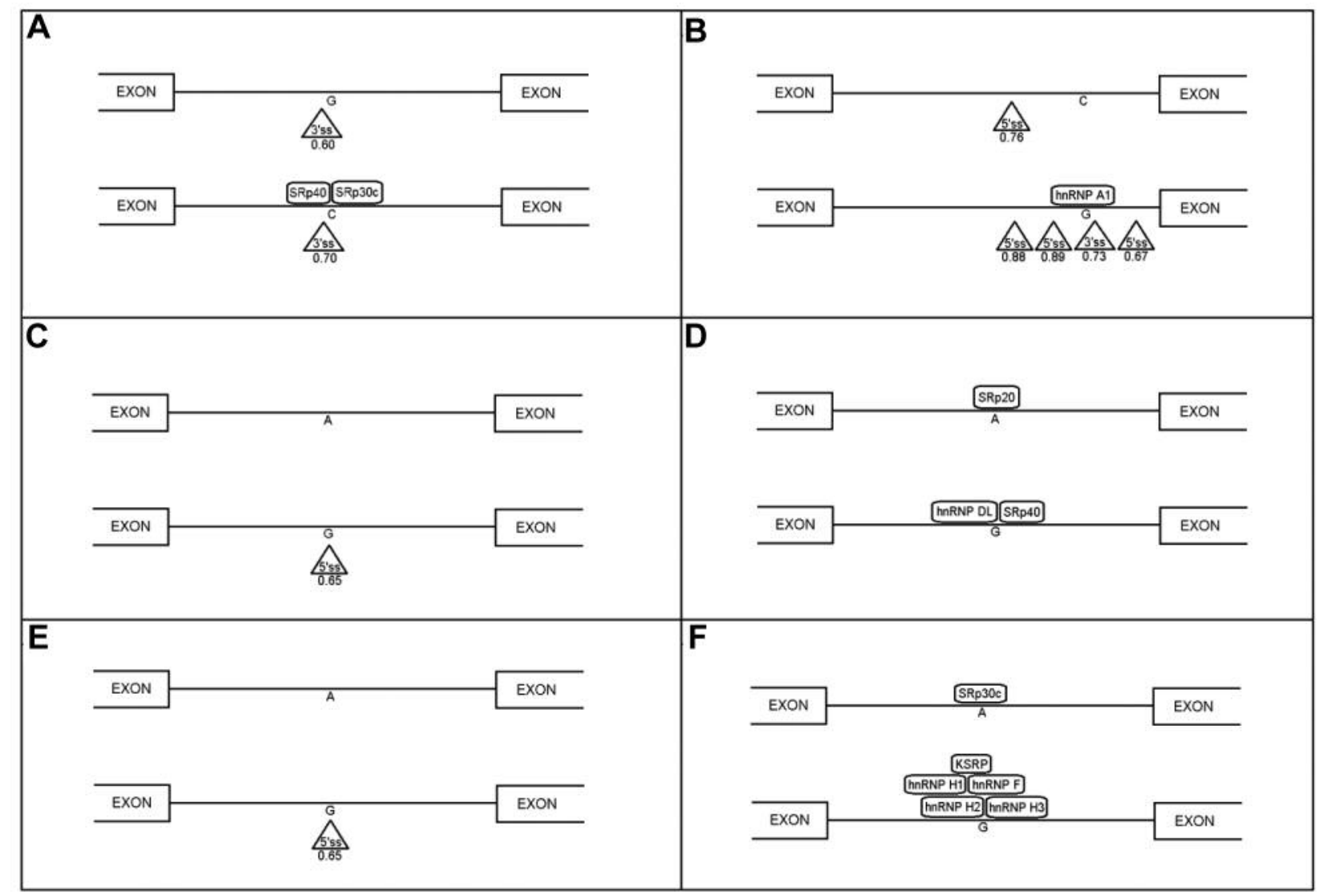

Figure 4. The identified ATG4A (A), ATG4B (B), ATG4C (C-E) and ATG5 $(F)$ single nucleotide polymorphisms (SNPs) and their predicted action on transcription regulation and splicing process.

rs6683832 of the $A T G 4 C$ autophagy related 4C, cysteine peptidase gene weakens the cryptic 5'ss (AACTTGgttctgtc) according to HSF so no splicing alterations are expected (Figure 4E).

rs9373839 of the ATG5 autophagy related 5 gene creates a binding site for KSRP, hnRNP F, hnRNP H1, hnRNP H2 and hnRNP H3 splicing proteins to the detriment of the SRp30c exonic enhancer. The binding of these proteins could reinforce the intron definition so no splicing effects are predicted (Figure 4F).

rs3804333 of the ATG5 autophagy related 5 gene allows the binding of the hnRNP A1 exonic silencer instead of SRp30c and SF2/ASF exonic enhancers without effects (Figure 5A).

rs490010 of the ATG5 autophagy related 5 gene prevents the binding of SRp20 and YB-1 splicing factors but this should not alter the Intron removal (Figure 5B).

rs6752107 of the ATG16L1 autophagy related 16-like 1 gene creates a weak cryptic 5'ss (cttaaggGTACAAAA) according to NNSPLICE and destroys a cryptic 3'ss (cttaagagTACAAA) according to (HSF). Moreover, this polymorphism reinforces another cryptic 5'ss (TTAAGGgtacaaaa) raising its score to 0.70. Although these changes could provoke alterations, these should be avoided by the predicted binding of SF2/ASF, hnRNP F, hnRNPC2, hnRNP H1, hnRNP H2 and hnRNP H3 proteins (Figure 5C).

rs10751215 of the ATG16L2 autophagy related 16-like 2 gene could cause the loss of SC35 and SF2/ASF splicing factors and the binding of SF1 and MBNL1 proteins. Since SpliceAid tool has predicted that in this tract there could be many other binding sites for SC35, SF2/ASF, SF1 and MBNL1 no splicing alterations are expected (Figure 5D).

rs10059011 of the IRGM immunity-related GTPase family, $M$ gene lies within the first non-coding exon (5'UTR) but no difference in terms of splicing sites or protein binding was predicted (Figure 5E). 


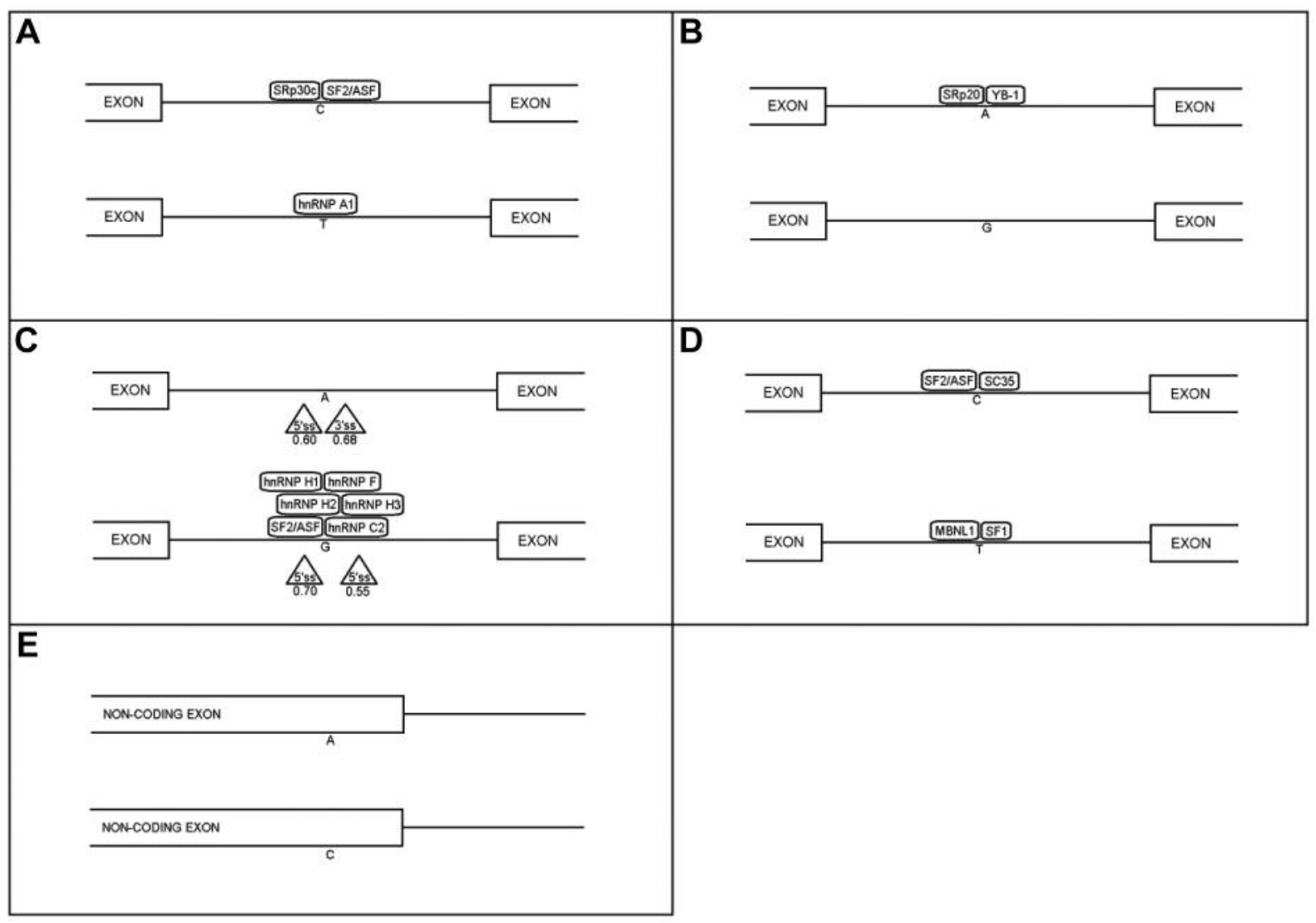

Figure 5. The identified ATG5 (A-B), ATG16L1 (C), ATG16L2 (D) and IRGM (E) single nucleotide polymorphisms (SNPs) and their predicted action on transcription regulation and splicing process.

\section{Discussion}

Several targeted agents are now available for the treatment of mRCC, but the lack of validated predictive and prognostic factors for the selection of patients who may benefit from pazopanib, rather than sunitinib, not only limits the possibility of optimizing the efficacy and tolerability of these drugs but also does not allow the design of personalized combined or sequential strategies for RCC patients. The transition from "one size fits all" to "a molecularly tailored" or "personalized" approach for advanced RCC patients represents a fundamental goal for the current translational studies.

In the last decade, SNPs have emerged as potential predictive and prognostic factors in patients with RCC treated with TKIs (27-33). Xu et al. observed that 3 polymorphisms in IL8 and HIFIA and 5 polymorphisms in HIF1A, NR1I2, and VEGFA were significantly correlated with the PFS and response rate (RR) of patients treated with pazopanib (27). In addition, they showed that genetic variants of $I L-8$ associated with higher gene expression conferred the ability to escape faster from the VEGFR blockade, resulting in poorer survival outcomes in pazopanib- or sunitinib-treated RCC patients (31).

In 2013, we revealed that pazopanib was able to induce autophagic cell death in RCC cell lines (13). Based on this evidence, we first tried to evaluate in this study the potential prognostic role of autophagic gene polymorphisms in patients treated with first-line pazopanib for metastatic disease. We showed that ATG4Ars7880351, ATG4C rs6670694, ATG4C rs6683832 and ATG5 rs490010 polymorphisms were correlated with the PFS of patients treated with pazopanib. Moreover, the presence of ATG16L2 polymorphism rs10751215 was significantly associated with a lower risk of developing clear cell RCC compared to the general population.

Furthermore, we reported the predicted molecular effects of some polymorphisms related to autophagy. Although no severe effects have been predicted, the preservation of the splicing patterns of these genes should be experimentally assessed in the renal tissue. In addition, since the splicing process is very specific, interesting differences could be found between healthy and pathologic tissues. 
Our study presents several limitations, including its retrospective nature, which is susceptible to bias in data selection and analysis, and the small number of evaluated patients. However, to the best of our knowledge, there are no studies focusing on the correlation between the referred SNPs and RCC risk and prognosis.

\section{Conclusion}

Our results suggest, for the first time, that inherited abnormalities in ATG4 and ATG5 genes influence the risk and response to treatment of RCC. However, we recognize that our findings will require confirmation in larger perspective epidemiological and clinical studies focusing on the prognostic significance of SNPs in patients with metastatic RCC.

\section{Conflicts of Interest}

The Authors declare to have no conflicts of interest.

\section{References}

1 Howlader N, Noone AM, Krapcho M, Miller D, Bishop K, Altekruse SF, Kosary CL, Yu M, Ruhl J, Tatalovich Z, Mariotto A, Lewis DR, Chen HS, Feuer EJ and Cronin KA: SEER Cancer Statistics Review, 1975-2013, National Cancer Institute. Bethesda, MD, 2016 http://seer.cancer.gov/csr/1975_2013. Accessed 10 January 2018.

2 Puente Vázquez J, Alonso Gordoa T, Moreno J, Poma L, Diaz Rubio E, Gomez A, Blazquez J and Gonzalez Larriba JL: New challenges in kidney cancer management: integration of surgery and novel therapies. Curr Treat Options Oncol 16: 337, 2015.

3 Santoni M, Conti A, Porta C, Procopio G, Sternberg CN, Basso U, De Giorgi U, Bracarda S, Rizzo M, Ortega C, Massari F, Iacovelli R, Derosa L, Masini C, Milella M, Di Lorenzo G, Atzori F, Pagano M, Buti S, De Vivo R, Mosca A, Rossi M, Paglino C, Verzoni E, Cerbone L, Muzzonigro G, Falconi M, Montironi R, Burattini L, Santini D and Cascinu S: Sunitinib, pazopanib or sorafenib for the treatment of patients with late-relapsing metastatic renal cell carcinoma. J Urol 193: 41-47, 2015.

4 Dranitsaris G, Vincent MD, Yu J, Huang L, Fang F and Lacouture ME: Sorafenib in advanced clear-cell renal-cell carcinoma. N Engl J Med 356: 125-134, 2007.

5 Motzer RJ, Hutson TE, Tomczak P, Michaelson MD, Bukowski RM, Rixe O, Oudard S, Negrier S, Szczylik C, Kim ST, Chen I, Bycott PW, Baum CM and Figlin RA: Sunitinib versus interferon alfa in metastatic renal-cell carcinoma. N Engl J Med 356: 115-124, 2007.

6 Sternberg CN, Davis ID, Mardiak J, Szczylik C, Lee E, Wagstaff J, Barrios CH, Salman P, Gladkov OA, Kavina A, Zarbá JJ, Chen M, McCann L, Pandite L, Roychowdhury DF and Hawkins RE: Pazopanib in locally advanced or metastatic renal cell carcinoma: results of a randomized phase III trial. J Clin Oncol 28: 1061-1068, 2010.

7 Rini BI, Escudier B, Tomczak P, Kaprin A, Szczylik C, Hutson TE, Michaelson MD, Gorbunova VA, Gore ME, Rusakov IG, Negrier S, Ou YC, Castellano D, Lim HY, Uemura H, Tarazi J, Cella D, Chen C, Rosbrook B, Kim S andMotzer RJ:
Comparative effectiveness of axitinib versus sorafenib in advanced renal cell carcinoma (AXIS): a randomised phase 3 trial. Lancet 378: 1931-1939, 2011.

8 Choueiri TK, Halabi S, Sanford BL, Hahn O, Michaelson MD, Walsh MK, Feldman DR, Olencki T, Picus J, Small EJ, Dakhil $\mathrm{S}$, George DJ and Morris MJ: Cabozantinib versus sunitinib as initial targeted therapy for patients with metastatic renal cell carcinoma of poor or intermediate risk: The Alliance A031203 CABOSUN Trial. J Clin Oncol 35: 591-597, 2017.

9 Hudes G, Carducci M, Tomczak P, Dutcher J, Figlin R, Kapoor A, Staroslawska E, Sosman J, McDermott D, Bodrogi I, Kovacevic Z, Lesovoy V, Schmidt-Wolf IG, Barbarash O, Gokmen E, O’Toole T, Lustgarten S, Moore L and Motzer RJ; Global ARCC Trial: Temsirolimus, interferon alfa, or both for advanced renal cell carcinoma. N Engl J Med 356: 2271-2281, 2007.

10 Motzer RJ1, Escudier B, Oudard S, Hutson TE, Porta C, Bracarda S, Grünwald V, Thompson JA, Figlin RA, Hollaender N, Urbanowitz G, Berg WJ, Kay A, Lebwohl D and Ravaud A; RECORD-1 Study Group: Efficacy of everolimus in advanced renal cell carcinoma: a double-blind randomised placebocontrolled phase III trial. Lancet 372: 449-456, 2008.

11 Amantini C, Morelli MB, Santoni M, Soriani A, Cardinali C, Farfariello V, Eleuteri AM, Bonfili L, Mozzicafreddo M, Nabissi M, Cascinu S and Santoni G: Sorafenib induces cathepsin Bmediated apoptosis of bladder cancer cells by regulating the Akt/PTEN pathway. The Akt inhibitor, perifosine, enhances the sorafenib-induced cytotoxicity against bladder cancer cells. Oncoscience 2: 395-409, 2015.

12 Kim C, Baek SH, Um JY, Shim BS and Ahn KS: Resveratrol attenuates constitutive STAT3 and STAT5 activation through induction of PTPE and SHP-2 tyrosine phosphatases and potentiates sorafenib-induced apoptosis in renal cell carcinoma. BMC Nephrol 17: 19, 2016.

13 Santoni M, Amantini C, Morelli MB, Liberati S, Farfariello V, Nabissi M, Bonfili L, Eleuteri AM, Mozzicafreddo M, Burattini L, Berardi R, Cascinu S and Santoni G: Pazopanib and sunitinib trigger autophagic and non-autophagic death of bladder tumour cells. Br J Cancer 109: 1040-1050, 2013.

$14 \mathrm{Hu}$ W, Yuan Q, Liu XH, Zhu HC, Lv SQ and Wang XH: Cyclophilin D-mediated apoptosis attributes to sorafenib-induced cytotoxicity in clear cell-renal cell carcinoma. Eur J Pharmacol 749: 142-150, 2015.

15 Morelli MB, Amantini C, Santoni M, Soriani A, Nabissi M, Cardinali C, Santoni A and Santoni G: Axitinib induces DNA damage response leading to senescence, mitotic catastrophe, and increased NK cell recognition in human renal carcinoma cells. Oncotarget 6: 36245-36259, 2015.

16 Hosokawa N, Hara T, Kaizuka T, Kishi C, Takamura A, Miura Y, Iemura S, Natsume T, Takehana K, Yamada N, Guan JL, Oshiro $\mathrm{N}$ and Mizushima N: Nutrient-dependent mTORC1 association with the ULK1-Atg13-FIP200 complex required for autophagy. Mol Biol Cell 20: 1981-1991, 2009.

17 Macintosh RL and Ryan KM: Autophagy in tumour cell death. Semin Cancer Biol 23: 344-351, 2013.

18 Notte A, Leclere L and Michiels C: Autophagy as a mediator of chemotherapy-induced cell death in cancer. Biochem Pharmacol 82: 427-434, 2011.

19 Mizushima N and Levine B: Autophagy in mammalian development and differentiation. Nat Cell Biol 12: 823-830, 2010. 
20 Santoni M, Pantano F, Amantini C, Nabissi M, Conti A, Burattini L, Zoccoli A, Berardi R, Santoni G, Tonini G, Santini $\mathrm{D}$ and Cascinu S: Emerging strategies to overcome the resistance to current mTOR inhibitors in renal cell carcinoma. BBA Cancer Rev 1845: 221-231, 2014

21 Reese MG, Eeckman FH, Kulp D, Haussler D: Improved splice site detection in Genie. J Comput Biol 4: 311-323, 1997.

22 Desmet FO, Hamroun D, Lalande M, Collod-Béroud G, Claustres $\mathrm{M}$ and Béroud CHuman: Splicing Finder: an online bioinformatics tool to predict splicing signals. Nucleic Acids Res 37: e67, 2009.

23 Piva F, Giulietti M, Nardi B, Bellantuono C and Principato G: An improved in silico selection of phenotype affecting polymorphisms in SLC6A4, HTR1A and HTR2A genes. Hum Psychopharmacol 25: 153-161, 2010.

24 Piva F, Giulietti M, Burini AB and Principato G: SpliceAid 2: a database of human splicing factors expression data and RNA target motifs. Hum Mutat 33: 81-85, 2012.

25 Giulietti M, Piva F, D'Antonio M, D’Onorio De Meo P, Paoletti $\mathrm{D}$, Castrignanò T, D’Erchia AM, Picardi E, Zambelli F, Principato G, Pavesi G and Pesole G: SpliceAid-F: a database of human splicing factors and their RNA-binding sites. Nucleic Acids Res 41: D125-D131, 2013.

26 Biernacka JM and Cordell HJ: Exploring causality via identification of SNPs or haplotypes responsible for a linkage signal. Genet Epidemiol 31: 727-740, 2007.

27 Xu CF1, Bing NX, Ball HA, Rajagopalan D, Sternberg CN, Hutson TE, de Souza P, Xue ZG, McCann L, King KS, Ragone LJ, Whittaker JC, Spraggs CF, Cardon LR, Mooser VE and Pandite LN: Pazopanib efficacy in renal cell carcinoma: evidence for predictive genetic markers in angiogenesis-related and exposure-related genes. J Clin Oncol 29: 2557-2564, 2011.

28 Garcia-Donas J, Esteban E, Leandro-García LJ, Castellano DE, del Alba AG, Climent MA, Arranz JA, Gallardo E, Puente J, Bellmunt J, Mellado B, Martínez E, Moreno F, Font A, Robledo M and Rodríguez-Antona C: Single nucleotide polymorphism associations with response and toxic effects in patients with advanced renal-cell carcinoma treated with first-line sunitinib: a multicentre, observational, prospective study. Lancet Oncol 12: 1143-1150, 2011.
29 Beuselinck B, Karadimou A, Lambrechts D, Claes B, Wolter P, Couchy G, Berkers J, Paridaens R, Schöffski P, Méjean A, Verkarre V, Lerut E, de la Taille A, Tourani JM, Bigot P, Linassier C, Négrier S, Berger J, Patard JJ, Zucman-Rossi J and Oudard S: Single-nucleotidepolymorphisms associated with outcome in metastatic renal cell carcinoma treated with sunitinib. Br J Cancer 108: 887-900, 2013.

30 Zhao R, Liu K, Huang Z, Wang J, Pan Y, Huang Y, Deng X, Liu J, Qin C, Cheng G, Hua L, Li J and Yin C: Genetic variants in Caveolin-1 and RhoA/ROCK1 are associated with clear cellrenal cell carcinoma risk in a chinese population. PLoS One 10: e0128771, 2015.

$31 \mathrm{Xu}$ CF, Johnson T, Garcia-Donas J, Choueiri TK, Sternberg CN, Davis ID, Bing N, Deen KC, Xue Z, McCann L, Esteban E, Whittaker JC, Spraggs CF, Rodríguez-Antona C, Pandite LN and Motzer RJ: IL8 polymorphisms and overall survival in pazopanib- or sunitinib-treated patients with renal cell carcinoma. Br J Cancer 112: 1190-1198, 2015.

$32 \mathrm{Chu}$ YH, Li H, Tan HS, Koh V, Lai J, Phyo WM, Choudhury Y, Kanesvaran R, Chau NM, Toh CK, Ng QS, Tan PH, Chowbay B and Tan MH: Association of ABCB1 and FLT3 polymorphisms with toxicities and survival in asian patients receiving sunitinib for renal cell carcinoma. PLoS One 10: e0134102, 2015.

33 Liu Y, Han X, Yu Y, Ding Y, Ni C, Liu W, Hou X, Li Z, Hou J, Shen D, Yin J, Zhang H, Thompson TC, Tan X and Cao G: A genetic polymorphism affects the risk and prognosis of renal cell carcinoma: association with follistatin-like protein 1 expression. Sci Rep 6: 26689, 2016. 